\title{
The Stress Analysis and Calculation Method of the Poles of Different Arrangement Styles in the Distribution Network Lines and the Research of "Abandoning Wires to Protect Electric Poles" Project
}

\author{
XIAO Kai ${ }^{1, a}$, HU Qingchun ${ }^{2, b}$, XIE Wenping ${ }^{1, c}$, \\ WEN Jiaqi ${ }^{2, d}$, LUO Xiaoyu ${ }^{1, e}$, LIN Zhisheng ${ }^{2, f}$ \\ ${ }^{1}$ Guangdong Power Grid Corporation Electric Power Research Institute, Yuedian Mansion, 8 \\ Shuijungang, Dongfeng East Road, Yuexiu District, Guangzhou, China \\ ${ }^{2}$ School of Mechanical and Automotive Eng, South China University of Tech, 381 Wushan Road, \\ Tianhe District, Guangzhou, China \\ axk0606@sina.cn, bhuqc@scut.edu.cn, ${ }^{\mathrm{c}}$ kevinxwp@foxmail.com \\ dwankaki@163.com, ${ }^{\mathrm{e}}$ Ixy86@163.com, ${ }^{\mathrm{f}}$ 824414996@qq.com
}

Keywords: Poles; Arrangement styles; Abandoning wires to protect electric poles; Implementation Abstract. The force situation of pole was analyzed in detail through the establishment of three-pole model, and the five-pole model was built on the basis of the former model. Besides, the influence of external factors including height difference, span, wind angle and line angle to the pole were studied, and the method to improve the force situation of pole: changing the pole arrangement styles was concluded in the research. At the end of the paper, the important points of "abandoning lines to protect electric poles" project were explained and illustrated by an example of implementation. It offered theoretical support to the implementation of "abandoning wires to protect poles" project.

\section{Introduction}

In our daily life, the distribution network lines play the important role to link electrical power system with power consumers. Guangdong, Guangxi and Hainan Provinces which is the area under administration of China Southern Power Grid are the typhoon prone area. Each time when typhoon landed, the lines would suffer different degrees of damage, even causing blackouts, and affect the safe and stable operation of power system seriously [1]. After the ice disaster in 2008, China Southern Power Grid proposed "abandoning wires to protect poles" concepts and strategies in the $35 \mathrm{kV}$ and below voltage distribution network lines when facing ice disasters.

Currently, the development of "Abandoning lines to protect poles" project is still in the preliminary stage, the current programs which are associated with the "abandoning wires to protect poles " project include: the Connecting Clamp Scheme invented by Guangzhou Kaineng Electric Industrial Company Limited and the integration device which can protect lines and poles or abandon wires to protect poles in the typhoon weather studied by the Guangdong Electric Power Science Research Institute.

At the present stage, a lot of "abandoning wires to protect poles" ideas are not useful, the main reason is the pole force situation is very complicated by the affection of the pole arrangement styles, weather and geography. The calculation method of pole stress in the actual environment was understood deeply in the paper by studying the influence of different arrangement styles in the distribution network lines to the stress of poles. Meanwhile, it can be learned the force situation of poles could be improved by changing the poles arrangement in this paper. These studies will provide theoretical basis and design methods to the popularization and application of the "abandoning wires to protect poles" project. 


\section{The Three-pole Model in the General Working Condition}

The force situation of a line unit including three poles in the general working condition was analyzed. It is supposed there is difference in height $\left(h_{A}, h_{B}\right)$, line angle $(\alpha)$ and $\operatorname{span}\left(L_{O A}\right.$ and $\left.L_{O B}\right)$ respectively on both sides of the line. Because the three-pole model belongs to the unit in a small range, it can be considered that wind is well-distributed and the angle between the direction of wind and the wire OA is $\theta$. The rule is the counterclockwise direction is positive, and the clockwise direction is negative. So the angle between the wind direction and the other wire OB is $\pi-\theta-\alpha$. It is supposed that the wind load ratio (the wind load on per unit length and per unit section) is $g_{4}$, the point $\mathrm{O}$ is the origin of the coordinate and angle bisector line is the $\mathrm{Y}$ axis to establish the rectangular coordinate system, as shown in figure 1:

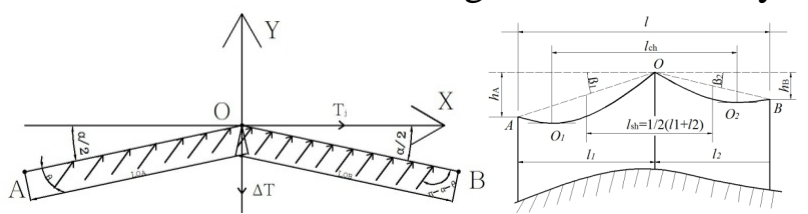

Fig1: Top view and main view of the line

The horizontal load of the Pole $\mathrm{O}$ is:

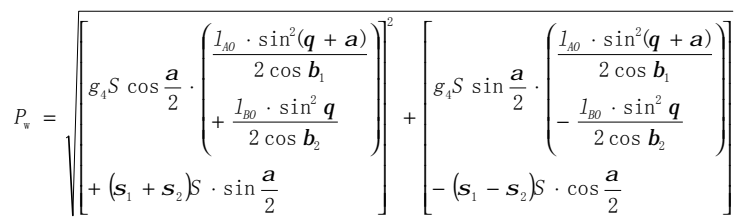

It should be noted that when the wind direction is the same as the angle load direction on the angle bisector line, as shown in figure2, the horizontal load of the Pole $\mathrm{O}$ is

$$
P_{w}=\sqrt{\left[\begin{array}{l}
g_{4} S \cos \frac{\alpha}{2} \cdot\left(\begin{array}{l}
\frac{l_{0 A} \cdot \sin ^{2}(\theta+\alpha)}{2 \cos \beta_{1}} \\
+\frac{l_{0 B} \cdot \sin ^{2} \theta}{2 \cos \beta_{2}}
\end{array}\right) \\
+\left(\sigma_{1}+\sigma_{2}\right) S \cdot \sin \frac{\alpha}{2}
\end{array}\right]^{2}+\left[\begin{array}{l}
g_{4} S \sin \frac{\alpha}{2} \cdot\left(\begin{array}{l}
\frac{l_{0 A} \cdot \sin ^{2}(\theta+\alpha)}{2 \cos \beta_{1}} \\
-\frac{l_{0 B} \cdot \sin ^{2} \theta}{2 \cos \beta_{2}}
\end{array}\right) \\
-\left(\sigma_{1}-\sigma_{2}\right) S \cdot \cos \frac{\alpha}{2}
\end{array}\right]}
$$

The vertical load of the pole $\mathrm{O}$ is:

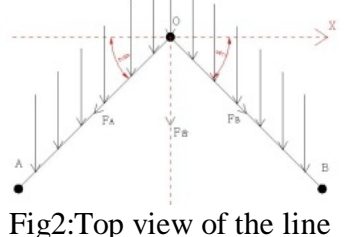

$$
G=g_{1} \cdot S \cdot\left[\frac{1}{2}\left(\frac{1_{A 0}}{\cos \beta_{1}}+\frac{l_{B O}}{\cos \beta_{2}}\right)+\frac{\sigma}{g} \cdot\left( \pm \frac{h_{A}}{l_{A O}} \pm \frac{h_{B}}{l_{B O}}\right)\right] ;
$$

The selection principle of plus or minus sign in the brackets is: compared with the wire suspension point of the calculated tower, it takes plus sign if the points of two sides is lower, otherwise it takes minus sign [2].

The force of suspension point in the Pole $\mathrm{O}$ is:

$$
F=\sqrt{G^{2}+P_{\mathrm{w}}^{2}}
$$

$P_{\mathrm{w}}$ is the wind load of the wire and ground wire, N. $\beta_{1}, \beta_{2}$ are the elevation angles of both sides to the middle pole respectively. $g_{4}$ is the wind load ratio in no ice weather, $\mathrm{N} /\left(\mathrm{m} \cdot \mathrm{mm}^{2}\right) . \mathrm{S}$ is the cross-sectional area of the wire, $\mathrm{mm}^{2}$.

Due to the presence of line angle, the angle force and unbalanced tension would come into being, and is shown in figue 1 and figure2. It is supposed that the direction of angle $\operatorname{load}_{T_{J}}$ is the X-axis direction. The direction of unbalanced tension is the Y-axis direction. Therefore, according to the load 
distribution diagram of the single straight column (figure 3), the bending moment of the any external force to any cross-sectional area on the pole could be calculated.

$$
\begin{aligned}
& M_{X}=(1+m) \cdot\left(\Sigma(G \cdot a)+\Sigma(P \cdot h)+P_{p X} \cdot h_{x} \cdot Z\right) \\
& \Sigma G \cdot a=G_{B} a_{B}+G_{D 1} a_{1}=\left(g_{B} S_{B} I_{c h B}\right) \cdot a_{B}+\left(g_{D} S_{D} I_{c h D}\right) \cdot a_{1} \\
& I_{c h B, D}=\frac{1}{2}\left(\frac{l_{O A}}{\cos \beta_{1}}+\frac{l_{O B}}{\cos \beta_{2}}\right)+\frac{\sigma}{g_{B, D}} \cdot\left( \pm \frac{h_{A}}{l_{O A}} \pm \frac{h_{B}}{l_{0 B}}\right) \\
& \Sigma P_{Z} \cdot h=P_{B Z} h_{1}+P_{D Z}\left(h_{2}+2 h_{3}\right)
\end{aligned}
$$

$$
\begin{aligned}
& =\sqrt{\left(\left(P_{D Y}+\Delta T_{B}\right)^{2}+\left(P_{B x}+T_{B J}\right)^{2}\right)} \cdot h_{1}+\sqrt{\left(\left(P_{D y}+\Delta T_{D}\right)^{2}+\left(P_{D x}+T_{D J}\right)^{2}\right)} \cdot\left(h_{2}+2 h_{3}\right)
\end{aligned}
$$

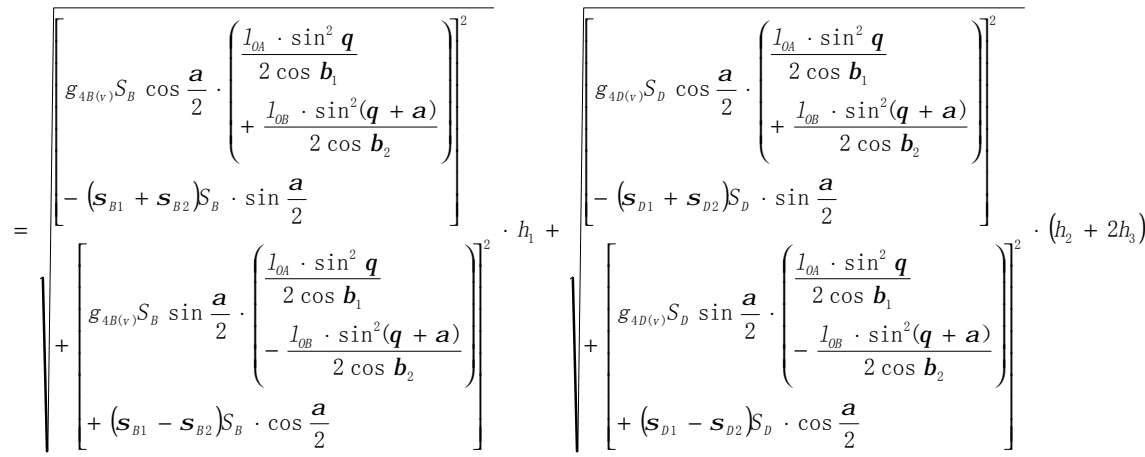

$$
\begin{aligned}
& g_{4(v) B, D}=9.8 \times \frac{\alpha_{F} C d_{B, D} V^{2}}{16 S_{B, D}} \times 10^{-3} ; \\
& P_{p x}=5.88 \times \frac{V^{2}}{16} \times \frac{D_{0}+D_{x}}{2} \\
& Z=\frac{2 D_{0}+D_{x}}{D_{0}+D_{x}} \times \frac{h_{x}}{3}
\end{aligned}
$$

Symbol $m$ is the additional coefficient of bending moment, the value is $12 \% \sim 15 \%$. G is the vertical load of pole, and $\mathrm{P}$ is the wind load of pole, N. $1_{c h B}, 1_{c h D}$ is the vertical span of wire and ground wire on pole, $\mathrm{m}$. $\mathrm{a}$ is the horizontal distance between the suspension point and pole, $\mathrm{m} . \sigma_{B}, \sigma_{D}$ is the stress of wire and ground wire, pa. $P_{p X}$ is the pressure of per unit length on the pole body above the calculated cross-sectional area $\mathrm{x}-\mathrm{x}, \mathrm{N} / \mathrm{m} . D_{0}$ is the diameter of the top of pole, m. $D_{x}$ is the diameter of the calculated cross-sectional area $\mathrm{x}-\mathrm{x}, \mathrm{m}$, and $D_{x}=D_{0}+\frac{h_{x}}{75} \cdot h_{x}$ is the height of pole body above the cross-sectional area $\mathrm{x}-\mathrm{x}, \mathrm{m} . \mathrm{Z}$ is the force arm of wind force to the cross-sectional area $\mathrm{x}-\mathrm{x}, \mathrm{m} .[1]$

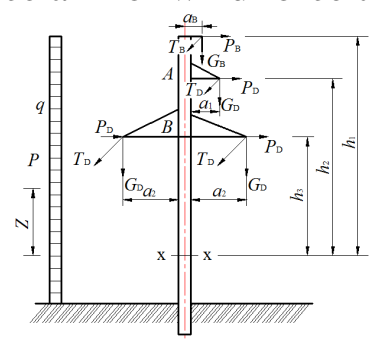

Fig3: The load distribution diagram of single pole

\section{The Five-pole Model in General Working Condition}

In the three-pole model in general working condition, only the force situation of middle pole could be analyzed. In fact, the real force situation of pole could not be reflected by the three-pole model because only the force of middle pole could be calculated. Therefore, the best method to analyze the force situation of poles comprehensively is to establish the five-pole model on the basis of the three-pole model. This method is useful to get the force maximum among the three intermediate poles.

The force situation of the line unit including five poles in the general working condition was analyzed. It is supposed there is difference in height $\left(h_{1}, h_{2}, h_{3}, h_{4}\right.$ and $\left.h_{5}\right)$, line angle $\left(\alpha_{1}, \alpha_{2}, \alpha_{3}\right)$ and span 
( $L_{A B}, L_{B C}, L_{C D}$ and $L_{D E}$ ) respectively among five poles of the line. The stress of the wires should be $\sigma_{1}, \sigma_{2}, \sigma_{3}$ and $\sigma_{4}$. It can be considered that the wind is well-distributed and the angle between the direction of the wind and the wire $\mathrm{AB}$ is $\theta_{1}$, the other angle between the direction of the wind and the wire $\mathrm{CD}$ is $\theta_{2}$. The rule is the counterclockwise direction is positive, and the clockwise direction is negative. It is supposed that the wind load ratio (the wind load on per unit length and per unit section) is $g_{4}$, as shown in figure 4:

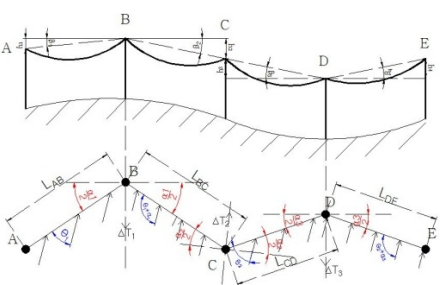

Fig4: Five-pole model

Now the force situation of five-pole model is analyzed:

(1) Three poles including Pole A,B,C

According to the three-pole model, because Pole B is the highest among the three poles A, $\mathrm{B}, \mathrm{C}$, the vertical load of the suspension point on Pole B is:

The horizontal load is:

$$
G_{B}=g_{1} \cdot S \cdot\left[\frac{1}{2}\left(\frac{l_{A B}}{\cos \beta_{1}}+\frac{l_{B C}}{\cos \beta_{2}}\right)+\frac{\sigma}{g} \cdot\left(+\frac{h_{1}}{l_{A B}}+\frac{h_{2}}{l_{B C}}\right)\right] ;
$$

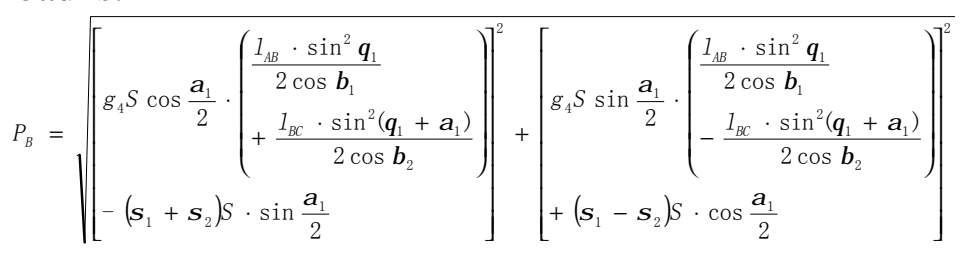

(2) Three poles including Pole B,C,D

Because Pole C is lower than Pole B, and higher than Pole D, the vertical load of the suspension point on Pole $\mathrm{C}$ is:

$$
G_{C}=g_{1} \cdot S \cdot\left[\frac{1}{2}\left(\frac{l_{B C}}{\cos \beta_{2}}+\frac{l_{C D}}{\cos \beta_{3}}\right)+\frac{\sigma}{g} \cdot\left(-\frac{h_{2}}{l_{B C}}+\frac{h_{3}}{I_{C D}}\right)\right] ;
$$

The horizontal load is:

$$
P_{C}=\sqrt{\left[\begin{array}{l}
g_{4} S \cos \frac{\alpha_{2}}{2} \cdot\left(\begin{array}{l}
\frac{l_{B C} \cdot \sin ^{2}\left(\theta_{1}+\alpha_{1}\right)}{2 \cos \beta_{2}} \\
+\frac{l_{C D} \cdot \sin ^{2} \theta_{2}}{2 \cos \beta_{3}}
\end{array}\right. \\
+\left(\sigma_{2}+\sigma_{3}\right) S \cdot \sin \frac{\alpha_{2}}{2}
\end{array}\right]^{2}+\left[\begin{array}{l}
g_{4} S \sin \frac{\alpha_{1}}{2} \cdot\left(\begin{array}{l}
\frac{l_{B C} \cdot \sin ^{2}\left(\theta_{1}+\alpha_{1}\right)}{2 \cos \beta_{2}} \\
-\frac{l_{C D} \cdot \sin ^{2} \theta_{2}}{2 \cos \beta_{3}}
\end{array}\right) \\
-\left(\sigma_{2}-\sigma_{3}\right) S \cdot \cos \frac{\alpha_{2}}{2}
\end{array}\right]}
$$

(3) Three poles including Pole C,D,E

Because Pole D is the lowest among these three poles, the vertical load of the suspension point on Pole $\mathrm{D}$ is:

$$
G_{D}=g_{1} \cdot S \cdot\left[\frac{1}{2}\left(\frac{l_{C D}}{\cos \beta_{3}}+\frac{l_{D E}}{\cos \beta_{4}}\right)+\frac{\sigma}{g} \cdot\left(-\frac{h_{3}}{l_{C D}}-\frac{h_{4}}{l_{D E}}\right)\right]
$$

The horizontal load is:

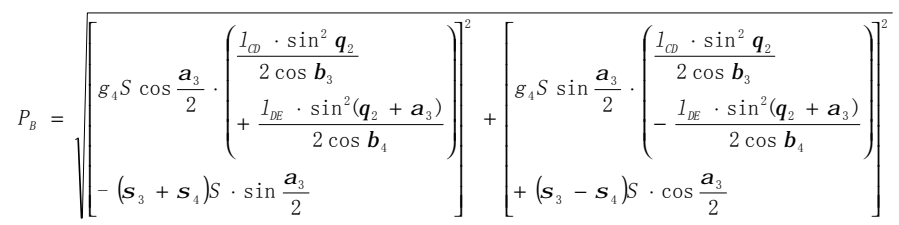

\section{The influence of environmental factors to the force situation of pole}

The typical wire is selected to explore the influence of height difference and span to force situation of pole. The pole height is 12 meters, the rank is K. The wire type is JKLYJ-10120, and wind speed is $35 \mathrm{~m} / \mathrm{s}$. The safety factor is $\mathrm{K}=5$. It is supposed that line angle is $0^{\circ}$ and wind angle is $90^{\circ}$. The 
relationship among the bending moment of pole, height difference and span is illustrated as figure $5,6,7,8$.

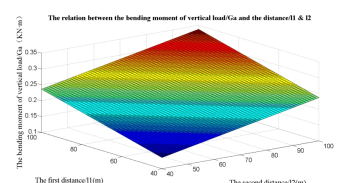

Fig5: When the height difference is 0 , the relationship between span and bending moment from vertical load

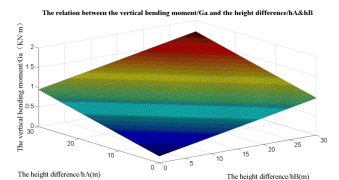

Fig7: When the span is constant, the relationship between height difference and bending moment from vertical load

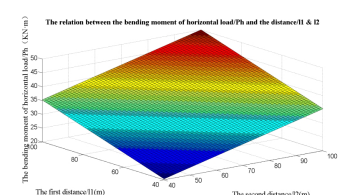

Fig6: When the height difference is 0 , the relationship between span and bending moment from horizontal load

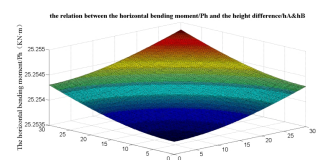

Fig8: When the span is constant, the relationship between height difference and bending moment from horizontal load

From the figures above, the bending moment from the horizontal and vertical load would increase if span and height difference increase. But the height difference affects mainly the bending moment from the vertical load, and there is less impact to the bending moment from the horizontal load. The reason is the vertical load is affected mainly by the height difference.

Therefore, the flat ground should be the first choice to establish the distribution network lines. To consider the safety and cost of construction, span selection should not be too long, otherwise it would increase the burden on the pole strength, and it is unwise to decrease span excessively. Because it would increase the number of poles dramatically, and increase the budget of the lines construction. In order to improve the capability of lines against typhoon, the span of single loop lines in town should be limited within 50m, the span in field should be limited within 70m. [3]

The line angle would come into being if the pole arrangement was limited. If the line angle could not be neglected, (as shown by figure9) the pole would be subjected to the combined action of wire tension and wind load from both sides. And wire tension and wind load are associated with the line angle. [4] Pole $\mathrm{O}$ is subjected to the bending moment from wind and wire tension, and the direction of wire tension of one side on straight pole is opposite to that of other side, so bending moment of wire tension from two sides could be offset. But the wire tension from both sides of Pole $\mathrm{O} F_{A}, F_{B}$ would convert into force $F_{\mathrm{h}}$, so the bending moment could be offset.

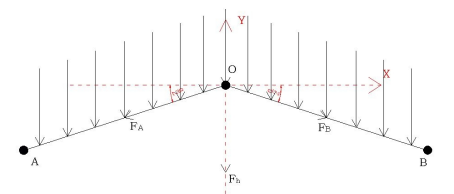

Fig9 Top view of the line

It is supposed that the height of pole is 12 meters and the rank is K. Speed of wind is $35 \mathrm{~m} / \mathrm{s}$, and the direction is the same as the minus $\mathrm{Y}$ direction. Here the safety factor is $\mathrm{K}=5$. In order to calculate the each wire under cross wind approximately, it is still assumed that the horizontal stress along the wire direction is equal. [5]

The range of line angle is $0^{\circ} \sim 14^{\circ}$, the bending moment from horizontal load is calculated, as shown in the table1. 
Tab1: Bending moment of small line corners to different wires

\begin{tabular}{|l|l|l|l|l|l|}
\hline $\begin{array}{l}\text { bending angle } \\
\text { moment(kNm) }\end{array}$ & $0^{\circ}$ & $1^{\circ}$ & $2^{\circ}$ & $3^{\circ}$ & $4^{\circ}$ \\
\hline \begin{tabular}{c} 
wire type \\
\hline JL/G1A-185/25
\end{tabular} & 18.50 & 12.53 & 6.54 & 0.86 & 6.18 \\
\hline JKLY-10/120 & 20.91 & 18.25 & 15.59 & 12.93 & 10.26 \\
\hline $\begin{array}{l}\text { JKLYJ-10/240 } \\
\text { bending angle } \\
\text { moment(kNm) }\end{array}$ & 26.09 & 21.99 & 17.88 & 13.77 & 9.66 \\
\hline \begin{tabular}{l} 
wire type \\
\hline JL/G1A-185/25
\end{tabular} & 12.17 & 18.18 & 24.19 & 30.21 & 36.23 \\
\hline JKLY-10/120 & 7.61 & 4.98 & 2.55 & 2.02 & 4.29 \\
\hline JKLYJ-10/240 & 5.60 & 2.01 & 3.88 & 7.89 & 12.02 \\
\hline $\begin{array}{l}\text { bending angle } \\
\text { moment(kNm) }\end{array}$ & $10^{\circ}$ & $11^{\circ}$ & $12^{\circ}$ & $13^{\circ}$ & $14^{\circ}$ \\
\hline \begin{tabular}{l} 
wire type \\
\hline JL/G1A-185/25
\end{tabular} & 12.17 & 18.18 & 24.19 & 30.21 & 36.23 \\
\hline \begin{tabular}{l} 
JKLY-10/120 \\
\hline JKLYJ-10/240
\end{tabular} & 7.61 & 4.98 & 2.55 & 2.02 & 4.29 \\
\hline
\end{tabular}

As for the bare wire, like type JL/G1A-185/25, between $0^{\circ} \sim 5^{\circ}$, the data decline at the beginning, and then increase. The data of $0^{\circ}$ is equal to that of $5^{\circ}$, when the angle goes on rising, the data continues to increase. Therefore, the best range of line angle for bare wire is $0^{\circ} \sim 5^{\circ}$, and the range of insulated wire should be controlled between $0^{\circ} \sim 10^{\circ}$.

In general, the relationship of line angle and wind angle to bending moment is illustrated in figure 10.

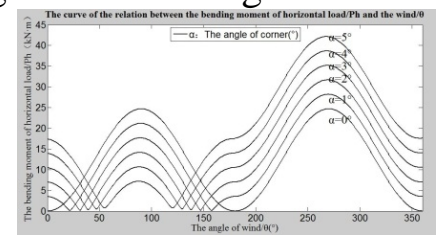

Fig10: The relationship among line corners, the angles of wind and bending moment of pole

From the figure above, when the range of line angle is between $0^{\circ} \sim 5^{\circ}$, the bending moment is influenced by wind angle mainly, The influence is: when the range of wind angle is $0^{\circ} \sim 180^{\circ}$, the data increases initially and decreases afterwards. When the angle is over $180^{\circ}$, the trend is much the same, but the maximum value is much bigger than that between $0^{\circ} \sim 180^{\circ}$. And the difference of the two maximum values is bigger if the line angle is bigger.

The reason is when the range is $0^{\circ} \sim 180^{\circ}$, the wind direction is opposite to the direction of angle load, so the direction of wind load is opposite to the direction of angle load, and loads would offset each other. When the range is $180^{\circ} \sim 360^{\circ}$, the wind direction change to be the same as that of angle load, therefore, the direction of two kinds of load is the same, and the loads would superpose each other.

\section{Research of the "Abandoning Wires to Protect Pole" Program}

In order to improve the ability of distribution network lines against typhoon, the measures to protect the key areas, adapt to local conditions and improve hierarchically in the general improvement programs against typhoon of distribution network lines. [6] But these programs could not to resist typhoon which exceeds the design conditions. According to some rules of $<$ Technical specification for design of overhead distribution lines >: The maximum design value of wind speed, for Guangdong 
Province, is $30 \mathrm{~m} / \mathrm{s}$, in fact, the value is far less than the speed $40 \mathrm{~m} / \mathrm{s}$ generated by the landing of Typhoon "Pearl" . [7] And "abandoning wire to protect pole" project could prevent before the arrival of typhoon to limit the damage as much as possible.

"Abandoning wire to protect pole" is defined as: A weakness point is set and controlled in the distribution network lines system. When suffering the working situation which exceeds the deign conditions, the weakness would be activated at first to protect the pole.

The device of "abandoning wire to protect pole" proposed by author is illustrated by figue 11 and 12 . The device is connected by the bolt component and porcelain pole arm, the weakness of this device is the detachable coils 2 which could deform by the external force. The function is achieved through the davit3 fall from the V-shaped clamping hole of the mobile column1. The process is: when the load along wire reaches the set value, the load transfers to the mobile column 1 through the davit3. Under the action of the transitional fillet of the mobile column1, the deformation of the detachable coils 2 would be achieved due to the expansion force, it would lead the detachable coils 2 slide to the large face on the step surface of the mobile column1. And then the davit 3 would be released from the V-shaped clamping hole, and drop out with the wire. So the pole is protected by releasing the wire tension. The force of the detachable coils 2 is less than the allowable load along the single wire, the difference is the safety margin of the external load on pole when suffering unexpected working conditions, the value depends on the historical disaster data on the region of the poles, meanwhile, and the lines construction cost, the transmission capacity and other factors should be taken into account. The other method is to make use of the theoretical calculation to ascertain the pole which bearing the larger load, and choose different ranks of pole to maintain consistency of safety margin with other poles when facing the typhoon disaster which exceeds the design condition

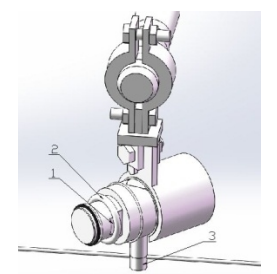

Fig11: Core component assembly drawing

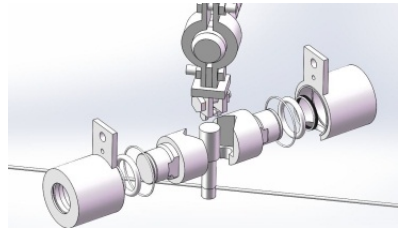

Fig12: Device explosion diagram

\section{Conclusion}

The force situation of pole in the actual environment was analyzed in detail by the research about the influence of different arrangement styles to the force situation of pole. Meanwhile, the measures of improving the pole force situation were understood, like changing span, height difference and line angle of the pole. It is good theoretical supplement to the "abandoning wire to protect pole" program. On the basis of theory, a "abandoning wire to protect pole" device presented in this paper, it offers the theoretical support to the implementation of the program.

\section{References}

[1] LI Tianwei, ZHAO Jianhua, CAI Yanfeng, LUO Bing, LIU Lei. Analysis on Design Wind Speed of Transmission Lines for Coastal Region of China Southern Power Grid. Southern Power System Technology, 2015, 9(6), 49-53

[2] Mao Xiaohua. The Basic Design of Transmission Line. Beijing: China Water \& Power Press, 2007:42-44,84-85

[3] Mei Weijie. The Cause Analysis and Preventive Measures to Accident of 10kV Distribution Network Lines Operation in Coastal Area. Scientific Innovation and Application, 2012, $29,152-153$

[4] ZHANG Hu, LI Jian, XU Weiyi, ZHOU Kui, ZHANG Fengshuo. Effectshuo of Wind Angle on the Horizontal Load for Tension Tower. Power System and Clean Energy, 2013, 29(7),12-15 
[5] Shao Tianxiao. Mechanical Calculation of Wires in Overhead Transmission Line. Beijing: China Power Press, 2003:183-184

[6] LUO Junping. Discussion on the Strengthening Measures Against Typhoon for the Power Distribution Network. Southern Power System Technology, 2013， 7 (3) ， 63-66

[7] Pan Caiyong. Poles Stress Analysis of 10kV Transmission Lines, Guangdong Electric Power, 2008,21(1),47-49 